\title{
Perceptions of Drama Integration in the Elementary Literacy Curriculum: A Bayesian Exploratory Factor Analysis
}

\author{
Lama Farran, Diana Mindrila \\ University of West Georgia
}

\begin{abstract}
The purpose of the current study was two-fold. First, the authors aimed to explore preservice teachers' attitudes toward integrating drama in the elementary school curriculum and to identify the latent dimensions underlying the attitudinal survey data. A second objective of the study was to demonstrate the application of exploratory factor analysis with a small sample using the Bayesian estimation procedure. The sample consisted of 32 preservice teachers (29 females and 3 males) enrolled in a university-based early childhood education program in the United States of America, who participated in several drama workshops over a period of two academic years. During the last semester of their teacher preparation program, preservice teachers were asked to complete a subset of the Drama-Infused Pre-service Teacher Experience Survey, which measures preservice teachers' attitudes and beliefs about using drama in their teaching. Models with one, two, and, three factors were estimated. The optimal solution showed very good fit to the data and included two factors (F1 and F2). Items in F1 refer to integrating drama to improve teaching, whereas items in F2 refer to integrating drama to enhance student outcomes. The location of each individual on the identified latent variables was estimated by computing mean plausible values. The identification of these two factors is a first step in the development of assessment tools for measuring attitudes regarding drama integration. Further, the current study demonstrates the application of Bayesian EFA, a new approach to factor analysis, which improves estimation accuracy with small sample sizes and non-normal data.
\end{abstract}

\section{Introduction}

Research examining teacher professional development suggests that preservice teachers benefit greatly from arts integration programs aimed at actively engaging children in authentic learning experiences [1, 2]. Specifically, Drama-focused professional development programs are thought to induce new ways of teaching and learning because they promote children's positive development across domains including language [3], social skills and self-regulation $[4,5]$. Importantly, teacher beliefs about and attitudes toward drama integration in the classroom may also impact teachers' behaviors, potentially affecting young children's developmental outcomes.

Drama helps children better understand and use language to enhance their early literacy development. Mages [6] posits that drama is paramount to language and literacy and proposes a causal model to explain the drama-language-literacy connection. Accordingly, when children dramatize stories, they use their bodies and voices to utter the words and imitate the actions of the characters, thereby improving their oral language and gaining a better appreciation of how interactions among the characters shape the story's events. As children proceed in their use of drama, they improve their own understanding of the interconnection between de-contextualized oral language and comprehension of word and text meaning. Preservice teachers, in turn, use drama to facilitate children's development of multiple components of language including semantic knowledge, narrative discourse, and syntactic understanding, which merge together to predict children's future literacy abilities [7].

In addition to its benefits in the domain of language, drama confers a cognitive advantage, helping children develop self-regulation which is a precursor to executive function skills. As the foundation for cognitive control, drama engages and challenges executive function skills, forcing the allocation of attention and working memory to enable children to respond flexibly to the incoming information from their immediate environment. Importantly, such allocation serves to inhibit children's impulses that deviate from the dramatic event, thus maintaining focus on the task at hand and consolidating the capacity for self-regulation, which ultimately lead to cognitive control and flexibility [8, 4].

Another well- documented benefit of drama is its potent impact on children's social skills [9]. Since social challenges present a barrier to accessing education and reaching optimal academic achievement in developing children, drama affords the perfect medium for social participation and integration, particularly for children who may be at risk for social difficulties such as children from diverse cultural and linguistic backgrounds and children with developmental disorders.

Despite the aforementioned benefits of drama, however, preservice teachers often believe their ability to use drama as a tool for teaching language, self-regulation, and social skills may be impeded due 
to teachers' lack of specialized drama training [10]. It is thus imperative to provide preservice teachers with drama-specific training and to assess their beliefs about and attitudes toward drama integration in the classroom as these may exert direct influences on children's developmental and academic outcomes.

\section{Objectives}

The purpose of the study was two-fold. First, the authors aimed to explore preservice teachers' attitudes toward integrating drama in the curriculum and to identify the latent dimensions underlying the attitudinal survey data. A second objective of the study was to demonstrate the application of exploratory factor analysis (EFA) with a small sample using the Bayesian estimation procedure.

\section{Theoretical Framework}

This paper draws upon the developmental theories of Bandura [11], Vygotsky [12], and Tomasello [13]. According to Bandura, teacher self-efficacy is the belief of the teacher's ability to accomplish a certain task and to perform at a certain level. It is related to the teacher's sense of power to engage in specific actions to achieve certain goals, which governs how teachers act, feel, reason, motivate themselves, and behave [11].

Teachers who lack basic knowledge in specific disciplines, are likely to be uncomfortable teaching the expected skills, and less likely to be competent at problem solving as they tend to believe that their knowledge base or their situation is far more challenging than it really is. As a result, they are unable or unwilling to infuse their knowledge in their curriculum. Thus, teacher beliefs of capabilities are thought to create potent influences on overall teacher effectiveness, which in turn, impacts student learning. Preservice teachers who do not expect to be successful at integrating drama into their classroom teaching practices are therefore likely to put forth less effort in learning new strategies, and to give up easily when encountering difficulties. In contrast, preservice teacher efficacy beliefs are raised if teachers perceive themselves as competent at infusing drama into their classrooms, which then increases teachers' willingness to learn new strategies and bolsters their expectations of themselves, likely resulting in successful drama integration and better student outcomes across developmental and academic domains. It is teachers' self-efficacy and confidence, coupled with teachers' development of drama strategies and skills that will determine the extent to which teachers will implement drama in their classroom teaching.

In addition to self-efficacy, the context in which teaching occurs also impacts student learning.
Vygotsky [12] posits that drama is an ideal context for promoting language and cognition based on the conceptualization that drama serves as a means of developing general representational abilities, which ultimately transfer to other domains of functioning. Teaching children dramatic play, however, has to be as intentional and systematic as teaching literacy and other content domains, while simultaneously be child-directed. Vygotsky suggests that dramatic play provides opportunities to learn not afforded by other classroom activities. Children's ability to make abstract transformations of roles in dramatic play translates into their ability to use abstract signs for ideas and objects, which is essential for oral and written language development in the early years.

The above views are also compatible with Tomasello's cultural learning theory, according to which children engage in social and communicative experiences (e.g., drama) that support the development of symbolic functioning and imitative learning within their culture, which are essential for language, social and cognitive skills development in early childhood. Children thus come to understand and share their intentions as they interact with others, leading them to develop empathy. Through these interactions, children develop the capacity to act on their own cognition, and to behave and re-describe their behaviors at higher abstract levels, thereby constructing more efficient social cognitive systems that pave the way to cultural learning [13].

\section{Method}

\subsection{Bayesian Exploratory Factor Analysis}

One of the most widely used statistical procedures in social sciences, factor analysis helps identify the latent constructs that underlie the data $[14,15]$. EFA is a data driven approach which is adequately employed when researchers have little theoretical or empirical evidence to formulate assumptions about the number of common factors or the variables included in each factor [15]. Although EFA was generally regarded as a procedure for large sample sizes, recent studies suggest that there are no absolute thresholds. Mundfrom, Shaw \& Ke [16] showed that factor analysis provides a reliable result with samples smaller than 50 when communalities are high and the number of factors is small. Gagne and Hancock [17] found that a sample size of 25 yielded no Heywood cases and no instances of nonconvergence with two factors and loadings above .8. Zeller [18] concluded that a sample size between 10 and 50 was sufficient for two factors and 20 observed variables. Similarly, Preacher \& MacCallum [19] showed a sample size of 10 can yield reliable EFA results.

Furthermore, recent developments in statistical software allow researchers to employ estimation 
methods that reduce estimation bias and do not require a large sample size, continuous variables, and a multivariate normal distribution [20]. The current study used the Mplus 7.1 statistical software to run EFA with the Bayesian estimation method and GEOMIN rotation. Bayes estimation employs Markov Chain Monte Carlo (MCMC) algorithms which use the conditional distribution of a set of parameters given other sets to make random draws of parameter values and approximate their joint distribution [21]. GEOMIN is an oblique rotation procedure, which uses an iterative algorithm to provide a good fit to the non-rotated factor loadings while minimizing a penalty function [22].

Bayesian estimation incorporates prior information to increase estimation accuracy by reducing the number of Heywood solutions [23, 24, 25). Unlike Maximum Likelihood (ML) estimation, Bayesian estimation does not rely on a multivariate normal distribution and performs better with small sample sizes [26, 27, 28]. Further, Bayesian estimation outperforms the Mean- and VarianceAdjusted Weighted Least Squares (WLSMV) method with categorical and ordinal data [28, 29]. The Bayesian procedure also allows the estimation of a wider range of models, and of models that are more computationally complex than ML [26, 28].

Models with one, two, and three factors were estimated. The optimal model was chosen based on interpretability, as well as by examining model parameters. After choosing the optimal number of factors, items that did not load on any factors as well as cross-loading items were sequentially deleted until a simple structure was reached.

Model fit was assessed using the Posterior Predictive $p$ value (PPP), which shows the extent to which the posterior distribution fits the data [28]. This probability is based on a fit index $f$ that shows the likelihood-ratio chi-square test of the Ho model against the H1 model [21]. In Mplus, the PPP is computed for every $10^{\text {th }}$ iteration used to describe posterior probabilities [28]. Mplus provides a $95 \%$ confidence interval for the difference in the $f$ statistic for the real and replicated data. When a model has excellent fit, the PPP value is close to 0.5 , and the middle of the $f$ statistic difference confidence interval is close to zero [21].

\subsection{Bayesian Plausible Values}

The location of each individual on the identified latent variables was estimated by computing mean plausible values. Frequentist estimation methods such as ML or Weighted Least Squares often yield negative residual variances with small sample sizes, which do not allow the computation of factor scores [30]. In contrast, the MCMC Bayes estimator allows the computation of factor scores by producing imputed plausible values for latent variables.
Asparouhov \& Muthén [30] showed that for a small sample size, the Bayes factor score estimates and standard errors are more reliable than those yielded by the ML estimator. Further, plausible values allow a more accurate estimation of factor variances and factor correlations for continuous latent variables [30]. For the current study, mean plausible values were plotted to illustrate the distribution of individuals in the current sample on the identified latent dimensions.

\section{Results}

The optimal solution included two factors labeled $\mathrm{F} 1$ and F2. Items in F1 refer to integrating drama to improve teaching, whereas items in F2 refer to integrating drama to enhance student outcomes. The items included in each factor along with the corresponding loadings are reported in Table 1. The GEOMIN factor correlation between the two factors was 0.29. Although this coefficient was small, it was statistically significant at the .05 level.

Table 1. Geomin rotated factor loadings

\begin{tabular}{|c|c|c|}
\hline \multirow[b]{2}{*}{ Survey Items } & \multicolumn{2}{|c|}{ Factor } \\
\hline & $\mathrm{F} 1$ & $\mathrm{~F} 2$ \\
\hline $\begin{array}{l}\text { The arts must be integrated within the } \\
\text { curriculum across content domains. }\end{array}$ & $0.944 *$ & \\
\hline $\begin{array}{l}\text { Drama-infused teaching is a way to } \\
\text { connect with students' diverse } \\
\text { learning styles. }\end{array}$ & $0.898 *$ & \\
\hline $\begin{array}{l}\text { Drama-infused teaching is a gateway } \\
\text { to students' cultural backgrounds. }\end{array}$ & $0.872 *$ & \\
\hline $\begin{array}{l}\text { Arts-infused teaching promotes } \\
\text { learning in the arts and other } \\
\text { disciplines. }\end{array}$ & $0.809 *$ & \\
\hline $\begin{array}{l}\text { The arts are important to learn in their } \\
\text { own right. }\end{array}$ & 0.606 & \\
\hline
\end{tabular}

Incorporating Drama strategies in the classroom enhances my future teaching of problem solving and critical thinking skills.

Incorporating Drama strategies in the classroom enhances my future students' self-regulation.

Participating in Drama workshops enhances my future classroom management skills.

Incorporating Drama strategies in the $0.960 *$ classroom enhances my future teaching of language development. Incorporating Drama strategies in the classroom enhances my future teaching of emergent literacy.

Note: * Significant at 5\% level

The posterior predictive value for the final model was 0.554, and the middle point of the $95 \%$ confidence interval $(-36.744 ; 36.401)$ for the 
difference between the observed and the replicated chi-squared values was close to zero, indicating excellent model fit. Figure 1 illustrates the distribution of mean plausible values on the two factors, and highlights cases with very high or very low values on one or both of the factors.

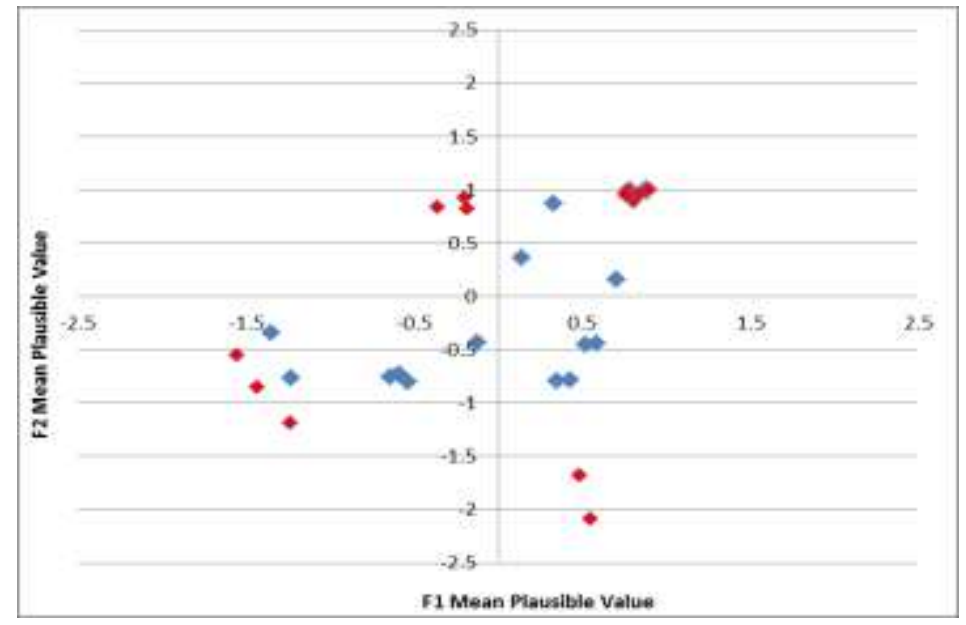

Figure 1. F1 and F2 mean plausible values

\section{Conclusions}

The results of this study support the idea that drama integration is best conceptualized as impacting various domains of teaching, a finding which is well substantiated in the emerging research on drama $[4,5]$. The results also concur with the aforementioned developmental theories. As selfefficacy theory suggests, drama integration is related to teacher beliefs, which likely impact teacher behavior and affect children's learning outcomes [11]. It could also be the case that children's outcomes themselves are influenced by the learning context that drama creates, which promotes children's construction of abstract and efficient cognitive representations that transfer to other domains of functioning such as language, selfregulation, cognitive, and social skills domains [12]. As such, teacher drama integration promotes the coconstruction of social-cognitive systems that allow children to understand others as intentional beings and to share their perspectives with others as part of their cultural learning [13]. As the current study revealed, the two dimensions in preservice teachers' attitudes towards integrating drama into their teaching were associated with each other. One dimension refers to the benefits of integrating drama into various aspects of teaching, whereas the second dimension reflects the role of integrating drama in improving student outcomes. The identification of these two components is a first step in the development of assessment tools for measuring attitudes regarding drama integration, which have the potential of informing intervention studies in the professional development of preservice teachers.
Further, the current study demonstrates the application of Bayesian EFA, a new approach to factor analysis, which improves estimation accuracy with small sample sizes and non-normal data.

\section{References}

[1] Cawthon, S., Dawson, K., \& Ihom, S. (2011). Activating student engagement through drama-based instruction. Journal for Learning through the Arts, 7(1).

[2] Saraniero, P., Goldberg, M. \& Hall, B. (2014). "Unlocking my creativity": Teacher learning in arts integration professional development. Journal for Learning through the Arts, 10(1).

[3] Golinkoff, R., Hirsh-Pasek, K., \& Singer, D. (2006). Play=Learning: A challenge for parents and educators. In D. Singer, R. Golinkoff, and K. Hirsh-Pasek (Eds.). Play Learning: How play motivates and enhances children's cognitive and social-emotional growth. New York, NY: Oxford University Press.

[4] Diamond, A., Burnett, S., Thomas, J., \& Munro, S. (2007). Preschool program improves cognitive control. Science, 318, 1387-1388.

[5] Bodrova, E., \& Leong, D. (1996). Tools of the mind: The Vygotskian approach to early childhood education. Englewood Cliffs, NJ: Merrill.

[6] Mages, W. (2006). Drama and imagination: a cognitive theory of drama's effect on narrative comprehension and narrative production. Research in Drama Education, 11 (3), 329-340.

[7] Huss, M., Verney, J., Fosker, T., Mead, N., \& Goswami, U. (2011). Music, rhythm, rise time perception 
and developmental dyslexia: Perception of musical meter predicts reading and phonology. Cortex: A journal Devoted to the Study of the Nervous System and Behavior, 47 (6), 674-689.

[8] Barnett, S., Jung, K., Yarosz, D., Thomas, J., Hornbeck, A., et al. (2008). Educational effects of the Tools of the Mind Curriculum: A randomized trial. Early Childhood Research Quarterly, 23 (3), 299-313.

[9] Peter, M. (2009). Drama: Narrative pedagogy and socially challenged children. British Journal of Special Education, 36 (1), 9-17.

[10] Jindal-Snape, D., \& Vettraino, E. (2007). Drama techniques for the enhancement of social-emotional development in people with special needs. Review of Research. International Journal of Special Education, 22 (1), 107-117. http://www.phusewiki.org/docs/ Conference 2014 SP Papers/SP03.pdf

[11] Bandura, A. (1997). Self-efficacy: The exercise of control. New York, NY: Freeman.

[12] Vygotsky, L. (1978). Mind in society: The development of higher mental processes. Cambridge, MA: Cambridge University Press.

[13] Tomasello, M., Carpenter, M., Call., J., Behne, T., \& Moll, H. (2005). Understanding and sharing intentions: the origins of social cognition. Behavioral and Brain Sciences, 28(5), 675-691.

[14] Gorsuch, R.L. (1974). Factor Analysis. Saunders, Philadelphia, PA.

[15] Fabrigar, L. R., Wegener, D. T., MacCallum, R. C., \& Strahan, E. J. (1999). Evaluating the use of exploratory factor analysis in psychological research. Psychological methods, 4(3), 272.

[16] Mundfrom, D. J., Shaw, D. G., \& Ke, T. L. (2005). Minimum sample size recommendations for conducting factor analyses. International Journal of Testing, 5, 159168.

[17] Gagne, P., \& Hancock, G. R. (2006). Measurement model quality, sample size, and solution propriety in confirmatory factor models, Multivariate Behavioral Research, 41(1), 65-83.

[18] Zeller, R. A. (2006). Statistical tools in applied research. Retrieved July 10, 2015, from http://www. personal.kent.edu/rzeller/Ch.\%2010.pdf

[19] Preacher, K. J., \& MacCallum, R. C. (2002). Exploratory factor analysis in behavior genetics research: Factor recovery with small sample sizes. Behavior Genetics, 32, 153-161.

[20] Finney, S. J., \& DiStefano, C. (2006). Non-normal and categorical data in structural equation modeling. Structural equation modeling: A second course, 269-314.

[21] Muthén, B., \& Asparouhov, T. (2010). Bayesian structural equation modeling: a more flexible representation of substantive theory. Psychological methods, 17(3), 313.

[22] Muthén, L. K., \& Muthén, B. O. (2012). Mplus. The comprehensive modelling program for applied researchers: User's guide, 5 .

[23] Lee, S.Y. (1981). A Bayesian approach to confirmatory factor analysis. Psychometrika, 46, 153-160.

[24] Martin, J.K. \& McDonald, R.P. (1975). Bayes estimates in restricted factor analysis: A treatment of Heywood cases. Psychometrika, 40, 505-517.

[25] Mayekawa, S. (1985). Bayesian factor analysis (ONR Technical Report No. 85-3). Iowa City: CadaResearch Group, University of Iowa.

[26] Schmitt, T. A. (2011). Current methodological considerations in exploratory and confirmatory factor analysis. Journal of Psychoeducational Assessment, 29(4), 304-321.

[27] Heerwegh, D. Small sample Bayesian factor analysis. Retrieved from: http://www.phusewiki.org/docs/ Conference\%202014\%20SP\%20Papers/SP03.pdf

[28] Asparouhov, T., \& Muthén, B. (2010). Bayesian analysis of latent variable models using Mplus. TechnicalnReport. Version 4. Retrieved from http://www.statmodel.com/download/BayesAdvantages18. pdf

[29] Asparouhov, T., \& Muthén, B. (2010). Bayesian analysis using Mplus: Technical implementation (Technical appendix). Los Angeles, CA: Muthén \& Muthén.http://www.statmodel.com/download/BayesAdvan tages18.pdf

[30] Asparouhov, T., \& Muthén, B. (2010). Plausible values for latent variables using Mplus. Unpublished. Accessed at: http://www. statmodel.com/download/ Plausible.pdf 